\title{
A EMPRESA PRIVADA COMO LOCAL SÓCIOOCUPACIONAL DO ASSISTENTE SOCIAL: REFLEXÕES ACERCA DA RESPONSABILIDADE SOCIAL
}

\author{
Alicia Santolini Tonon, Maria Eduarda Costa Ferri \\ Faculdades Integradas "Antônio Eufrásio de Toledo". Curso de Serviço Social, Presidente Prudente - SP. E-mail: \\ alicia santolini@hotmail.com
}

\section{RESUMO}

O presente artigo é resultado dos estudos realizados na disciplina de Oficina de Empresa no curso de Serviço Social das Faculdades Integradas "Antônio Eufrásio de Toledo" de Presidente Prudente - São Paulo. A presente pesquisa tem como objetivo realizar uma discussão sobre a atuação do assistente social na empresa privada capitalista, destacando a trajetória da profissão e sua atuação neste local sócioocupacional. E, ainda, realizar reflexões acerca da responsabilidade social neste local de atuação, fazendo um resgate histórico desta atividade dentro da empresa. Para concretizar este objetivo, utilizou-se pesquisa bibliográfica e eletrônica direcionadas ao tema. 0 método utilizado nesta pesquisa é o dialético, sendo assim, a teoria crítica.

Palavras-chave: Responsabilidade Social. Empresa. Capitalismo. Assistente Social.

\section{A PRIVATE COMPANY AS THE LOCAL SOCIO-OCCUPATIONAL SOCIAL WORKER: REFLECTIONS OF SOCIAL RESPONSIBILITY}

\begin{abstract}
This article is the result of studies conducted in the discipline of Workshop Company in the course of Social Service of Integrated Schools "Antônio Eufrásio de Toledo" Presidente Prudente - São Paulo. This research aims to conduct a discussion on the role of social worker in private capitalist enterprise, highlighting the history of the profession and its socio-occupational activity in this location. And also, to reflect on the social responsibility at the place of work, doing a historical restoration of this activity within the company. To achieve this goal, we used bibliographic and electronic research directed to the topic. The method used in this research is dialectical, thus being critical theory.

Keywords: Social Responsibility. Company. Capitalism. Social Worker.
\end{abstract}




\section{INTRODUÇÃO}

Justifica-se escrever sobre a referida temática pois o assistente social possui um leque enorme de locais socioocupacionais, inclusive a empresa. Há necessidade de destacar que, independentemente do local no qual o assistente social está inserido, ele necessita atuar com respaldo teóricometodológico, técnico-operativo e éticopolítico, tendo como base o projeto éticopolítico profissional, contudo, a empresa possui características diferenciadas das instituições públicas portanto, a intervenção deste profissional será mais específica.

O objetivo desta pesquisa é elencar algumas reflexões acerca da responsabilidade social no âmbito da empresa privada no contexto da sociedade capitalista, bem como, a atuação do assistente social neste espaço. Assim, é imprescindível discutir sobre sua atuação dentro desta instituição, por se tratar de um espaço que fomenta o sistema societário vigente. Para materializá-lo, utilizou-se pesquisa bibliográfica e eletrônica pertinentes ao tema. O método utilizado foi o dialético, portanto, a teoria crítica.

O texto foi estruturado em cinco itens: O primeiro é a introdução com intuito de expor a organização deste artigo. 0 segundo discorreu de forma breve a conceituação da empresa na sociedade capitalista. Já o terceiro acometeu a responsabilidade social no âmbito empresarial. O quarto abordou a atuação do assistente social neste local sócioocupacional com enfoque frente à responsabilidade social empresarial. E o texto se encera com as considerações finais.

\section{BREVE CONCEITUAÇÃO DA EMPRESA} PRIVADA NA SOCIEDADE CAPITALISTA

Empresa pode ser delimitada como sendo "um conjunto sociocultural complexo, organizado para a realização de serviços, fabricação de coisas, transformação ou extração de produtos da natureza" (OLIVEIRA, 2002, p. 251) Ou seja, é uma unidade social que representa uma forma de atividade econômica dentro de sistema capitalista vigente, na qual transforma a natureza em produtos ou oferece serviços, possui como grande característica a obtenção de lucro atendendo as exigências de consumo do contexto econômico-social da sociedade.

Trata-se de uma instituição na qual "os dirigentes e os assalariados estabelecem uma relação entre defesa de seus interesses e o alcance de fins reconhecidos como legítimos por uma determinada sociedade". (RICO, 1982, p. 47) Sendo assim, é um espaço contraditório que estabelece uma relação de poder entre empregador e proletariados, fomentando o capitalismo e o ciclo de 
produção e, esta instituição espera ser reconhecida pela sociedade enquanto empresa de qualidade.

Há três tipos de empresas: a pública, a privada e a mista, contudo, este estudo tem enfoque na empresa privada, que se caracteriza como sendo aquela que o proprietário possui todos os direitos sobre a mesma. Sendo assim, é ele quem decide as direções que a produção irá percorrer e aponta quem permanece enquanto trabalhador contratado, sendo assim, há uma competitividade entre os funcionários.

Os conflitos que permeiam a relação patrão versus funcionários, resultado de interesses antagônicos, basicamente são definidos porque o dono da empresa visa produção e lucro exacerbado. Já o assalariado visa cumprir sua carga horária, vendendo sua força de trabalho em troca de um salário para se sustentar.

Fica claro que as empresas possuem intensão de produzir e lucrar cada vez mais, contudo, o setor empresarial tem realizado algumas ações voltadas para a cidadania e defesa dos direitos da sociedade e, isto representa, tomar para si responsabilidades que são de caráter Estatal frente às expressões da questão social. Estas ações podem ser realizadas através da responsabilidade social, na qual será o tema central do próximo item.

\section{BREVE CONTEXTUALIZAÇÃO}

DA RESPONSABILIDADE SOCIAL NO ÂMBITO EMPRESARIAL

A responsabilidade social empresarial encontra-se no âmbito do terceiro setor, ainda possui discussões sobre seu conceito, por se tratar de um tema complexo e contraditório. Contudo, pode ser definida como sendo um:

estilo de gestão
caracterizado pela ética e
transparência na relação da
empresa com todos os seus
públicos, sincronizando suas
metas empresariais ao
desenvolvimento
sustentável da sociedade,
respeitando as diferenças,
esforçando-se pelo
estabelecimento de uma
sociedade mais justa e,
buscando garantir os
recursos naturais e culturais
que permitam à sociedade
a sua manutenção e
evolução através das
próximas gerações.
(HILSDORF, 2013)

Portanto, trata-se de uma ação social realizada pelas empresas privadas como forma de enfrentar as desigualdades emergentes na sociedade, abordam temas direcionados às comunidades, ao meio ambiente e sustentabilidade, esportes, ou indivíduos que vivenciam alguma expressão da questão social.

A responsabilidade social começou a fazer parte das empresas em meados da 
década de 80, através da ascensão do processo tecnológico que foi denominado globalização econômica e, mais uma vez, este aspecto rebateu nas organizações empresariais.

As empresas privadas precisavam, então, encontrar estratégias e elaborarem novas rumos de obtenção de lucro e, cada "vez mais a qualidade do produto está relacionada à relação da empresa com a sociedade e seu comportamento ético e esses fatores determinam o comportamento dos consumidores" (PAES, 2003, p. 25) Ou seja, os consumidores começaram a exigir que estas organizações realizassem trabalhados voltados ao meio social e valorizavam estas ações.

Neste contexto, as empresas privadas: começaram a promover um discurso politicamente correto, pautado na ética, implementando ações sociais que podem significar ganhos em condições de qualidade de vida e trabalho para a classe trabalhadora ou, simplesmente, podem se tornar um mero discurso de marketing empresarial desvinculado de uma prática socialmente responsável. (MIFANO, 2002, s.p.)

Sendo assim, a responsabilidade social empresarial é envolvida (e, algumas situações, unicamente) em um marketing social para fomentar as vendas, fazendo com que o cidadão compre os produtos ou opte por serviços de sua empresa acreditando que estará contribuindo com uma causa. Deste modo, podemos afirmar que a responsabilidade social "trata-se de uma questão estratégica o investimento na área social, pois as empresas ao serem reconhecidas como socialmente responsáveis tendem a conseguir diferenciais de competitividade e uma vez tendo a imagem valorizada [...]" (RICO, 2004, s.p.)

Neste contexto, é possível afirmar que executar ações de responsabilidade social é benevolente para a empresa no sentido de fomentar sua produção e, assim, aumentar sua lucratividade. Contudo, a sociedade deve ter um olhar crítico para com estas ações pois, ao mesmo tempo em que está trazendo benefícios e apoiando uma causa, pode estar mascarada para lucrar financeiramente. Alguns profissionais são requisitados para realizarem este tipo de função dentro do espaço empresarial e o assistente social, no qual será o foco do próximo item, pode ser um deles.

\section{A ATUAÇÃO DO ASSISTENTE SOCIAL EM ÂMBITO EMPRESARIAL FRENTE À RESPONSABILIDADE SOCIAL}

Há necessidade de destacar neste momento que, este estudo, tem como foco realizar uma discussão relacionada à 
intervenção do assistente social no âmbito empresarial, no qual foi contratado para realizar ações de responsabilidade social em uma empresa privada.

No que tange $o$ contexto das empresas, o assistente social é requisitado, significativamente em meados da década de 70, para executar ações com o objetivo de manutenção da força de trabalho, no sentido de interferir na vida cotidiana do trabalhador, tanto no contexto da empresa quanto doméstico e social, com intuito de alterar os hábitos, atitudes e comportamentos dos mesmos objetivando sua adequação ao processo de produção. $E$, também, chamado para mediar possíveis conflitos entre capital e trabalho.

Segundo Mota (2010, p.69) o "assistente social entra na empresa para subsidiar o trabalho improvisado, empírico e desarticulado, realizado pelos funcionários administrativos". Neste sentido, é possível afirmar que o assistente social possui uma formação capaz de proporcionar respaldo teórico e prático para atuar com eficácia e de maneira diferenciada na empresa.

Contudo, esta atuação é exigida para atender "contraditoriamente, tanto às necessidades do capital - contratante dos serviços profissionais - como às do trabalho, pela via de uma intervenção voltada a considerar as necessidades básicas dos trabalhadores e de suas famílias.". (AMARAL,
2004, p.3) Destaca-se, então, a contradição posta na atuação do assistente social no âmbito empresarial, na qual vende sua força de trabalho, atua para atender os interesses do patrão e, ao mesmo tempo, o respaldo em sua formação na qual firma o compromisso com a classe trabalhadora.

No âmbito da empresa, enquanto local sócioocupacional, faz-se necessário que o assistente social se utilize de instrumentais e estratégias para demonstrar pontos concretos em suas ações para o empregador. Respeitar os limites institucionais, descobrindo meios de aproximação com o empregador e com os trabalhadores, estabelecendo vínculos para que seja possível executar as ações. É válido ressaltar que o assistente social dentro de uma empresa privada também encontra-se em situação de assalariado, portanto, tanto possui funções que são exigidas pelo patrão e que, se não forem cumpridas, pode leva-lo à demissão.

O assistente social, dispõe de instrumentais para como planejamento, organização, aplicabilidade e avaliação, além disso, possui respaldo teórico-metodológico, técnico-operativo e ético-político para elaborar e desenvolver planos, programas e projetos no que tange a responsabilidade social.

Através da bagagem de sua formação e a leitura de forma crítica da realidade, o 
assistente social é capaz de abranger a responsabilidade social de maneira qualificada, que vá de encontro com as intencionalidades do empregador mas que, acima de tudo, seja capaz de transformar a realidade dos indivíduos que vão fazer parte destas atividades.

\section{CONSIDERAÇÕES FINAIS}

Através da pesquisa é possível compreender que as empresas privadas são espaços de competividade e produção, nas quais possuem como essência o lucro e fomentam o capitalismo vigente. $\mathrm{O}$ assistente social em uma empresa privada, contribui para mediar as tensões que interferem na relação patrão versus funcionários, sendo capaz de atender as exigências do patrão e as demandas trazidas pelos trabalhadores.

A responsabilidade social se trata de uma estratégia da gestão da empresa, que buscam minimizar as expressões da questão social, culpabilizado o Estado pelos problemas sociais e mostrando que estão preocupadas em resolvê-los. Contudo, estas ações acontecem revestidas pelo marketing social no qual atribui uma imagem de cidadania e moralidade por parte da empresa privada, fazendo com que a mesma seja a escolha dos consumidores com intuito de produzir e lucrar cada vez mais.

Até porque, a questão social trata-se de responsabilidade do Estado, que deve enfrenta-la através de políticas públicas e sociais com abrangência nacional e de qualidade. Neste contexto, a responsabilidade social empresarial tem como grande consequência a desresponsabilização do Estado frente às expressões da questão social e a camuflagem das contradições estruturais presentes na sociedade e causadas pelo capitalismo vigente. Não é possível generalizar, pois acredito que qualquer um possa refletir e contribuir para alguma causa, mas, a responsabilidade social empresarial, na concepção desta pesquisadora, é não na vertente da solidariedade, e sim da caridade, o que não implica em justiça social.

É cabível que a responsabilidade social empresarial seja encabeçada por um profissional de Serviço Social, pois em sua formação, adquiriu conhecimento que permite uma visão crítica da realidade em sua totalidade e, mesmo assim, terá que encontrar estratégias de atender as exigências do empregador e ações de transformação social para os funcionários.

No mesmo contexto, o assistente social precisa ser cauteloso em atuar em uma empresa no sentido não perder sua personalidade enquanto profissional, ou seja, realizar sua prática profissional pautada no Projeto Ético-Político, no Código de Ética Profissional e nas demais legislações que baseiam a profissão. 


\section{REFERÊNCIAS}

AMARAL, A. S. ; CESAR, M. J. . O Trabalho do Assistente Social nas empresas Capitalistas. Serviço Social: Direitos Sociais e Competências Profissionais, 2004.

ANTUNES, R. Adeus ao trabalho?: ensaio sobre as metamorfoses e a centralidade do mundo do trabalho. 13. ed. rev. e ampl. São Paulo: Cortez, 2008.

BRASIL, Constituição (1988). Constituição da República Federativa do Brasil. Brasília: Senado, 1988.

MATERIAL utilizado em sala de aula na disciplina Oficina de Empresa do sétimo termo do curso de Serviço Social das Faculdades Integradas "Antônio Eufrásio de Toledo" de Presidente Prudente/São Paulo.

MIFANO, G. A crise mundial de confiança nas empresas: uma questão de Responsabilidade Social. Disponível em:

<http://www.ethos.org.br/docs/conceito pr aticas/publicações/Debates/a crisemundial.p pt>. Acesso em: 20 maio 2014.

MOTA, A. E. S. (org). Feitiço da ajuda. 6.ed. São Paulo: Cortez, 2010.

OLIVEIRA, S. L. Sociologia das organizações: uma análise do homem e das empresas no ambiente competitivo. São Paulo: Pioneira Thomson Learning, 2002.

PAES, A. A Responsabilidade Social Empresarial (RSE): espaço de intervenção profissional do Serviço Social. 2003. Trabalho de Conclusão de Curso (Graduação) -. Faculdade de Serviço Social da PUC-SP, São Paulo.RICO, E. de M. Teoria do Serviço Social de Empresa: objeto e objetivos. São Paulo: Cortez, 1982.
Recebido para publicação em 12/08/2014 Revisado em 03/09/2014

Aceito em 23/09/2014 